\title{
Ridership and Revenue Implications of Free Fares for Seniors in Northeastern Illinois
}

\author{
Paul Metaxatos, University of Illinois at Chicago
}

\begin{abstract}
This paper reports on the ridership and revenue impacts for transit providers of a short-lived Seniors Free Ride Program in the Chicago metropolitan area. The discussion presents survey-free and survey-based approaches specifically developed to capture such effects during the program implementation. The analysis shows that instituting a free fare policy for seniors expectedly increased the demand for and associated costs of providing the service. In particular, the program had attracted approximately 75 percent additional senior rides at an associated cost of between $\$ 26.1$ and $\$ 78.6$ million. The Illinois legislature modified the program in 2011 to run as a means-tested program partially because of cost considerations. However, the methodology presented remains relevant for existing and future fare-free programs.

\section{Introduction}

By 2020, 40 percent of the U.S. population will be senior citizens; many will be unable to drive. In fact, one-fourth of today's $75+$ age group does not drive. Moreover, between 2010 and 2030, it is estimated that the "baby-boomer" cohort (65+ years) will grow four times faster than the population as a whole in those two decades (U.S. Bureau of the Census 2008). Seniors "who can confidently use public transportation to get to their appointments, shopping destinations, and to visit friends will be able to live in their own homes much longer than those who are reliant on others for their transportation needs" (Ammon 2005).
\end{abstract}


Meeting the transportation needs of seniors is a major community objective as well as a national goal. Public transportation and related travel options represent a lifeline for seniors, linking them with family, friends, and a changing society. To accommodate the growing senior population, several cities have created opportunities and approaches to enable this age group to become mobile by using public transportation.

However, tailoring public transportation to meet seniors' needs has been somewhat challenging for public transit operators, and many are still researching the best methods and services to this end. Some public transit operators are giving seniors incentives to ride public transportation for discounted prices, and a few operators are offering free rides for seniors. Such was the case in the state of Illinois that enacted a Seniors Free Ride Program in 2008. In the six-county Chicago region, the program was funded by an additional 0.25 percent sales tax and, administratively, it was added to the existing reduced fare program. The program allowed persons over the age of 65 to ride the state's transit systems free, with important repercussions for transit service providers, especially in the Chicago area.

Indeed, one of the main concerns of agencies contemplating fare-free transit programs is the effect on ridership, revenues, and costs. Clearly, careful ex ante evaluations of such impacts are desirable. Occasionally, however, there is a need to evaluate such impacts during the implementation of a fare-free program. In this regard, this paper discusses ridership and revenue impacts of the program on the Chicago area public transit operators based on findings from a study published elsewhere (Dijohn et al. 2010).

Note that the free-fare program in Illinois was modified in 2011 to run as a meanstested program partially because of cost considerations. However, numerous free-fare transit programs are still in operation (Volinski 2012), and many other agencies, for various reasons, may be contemplating including free-fare options in their operations. In this light, the presentation provides details about the methods specifically developed and implemented to quantify the relevant ridership and revenue of such programs adding thereby to the toolkit of transit planners.

\section{Literature Review}

\section{Attitudes of Seniors toward Mobility}

In a survey done in 2005 by the American Public Transportation Association (APTA) of people 65 years or older, 98 percent of respondents felt that maintaining their independence is "extremely important," yet seniors worry about their mobil- 
ity options and being stranded and cut off from family, friends, medical help, community activities, etc. (APTA 2005). When seniors were asked about their mobility options, although they recognized the importance of public transportation in their community, they preferred to drive and felt there was a lack of transportation options within their community.

Surprisingly, the survey found that about 60 percent of seniors would use public transportation services if they were easily available in their neighborhoods, and 83 percent of participants would use public transit if it provided faster access to their lifestyles needs: doctor's appointments, entertainment, shopping, and visiting with friends and family. Furthermore, 80 percent of the seniors surveyed believed that public transit is easier and more convenient than driving and 82 percent felt it is a better option at night (APTA 2005).

\section{Industry Experiences with Fare Free Programs}

There are only three large metropolitan areas that permit seniors to ride free: Philadelphia, Pittsburgh, and Miami. All have experienced similar ridership trends as the Chicago region. In addition, there were numerous, small urban, rural, and paratransit operations that offer free service (Volinski 2012) but that were not directly comparable with fare-free operations running at the time in the Chicago region.

In August 2007, the Southeastern Pennsylvania Transportation Authority (SEPTA) expanded the "free" travel hours for seniors to $24 \mathrm{hrs} /$ day (from $22 \mathrm{hrs} /$ day) on SEPTA buses, trolleys, and subway-elevated lines with valid Medicare Card, Railroad Retirement Card, or Transit ID Card. Prior to this change, seniors traveled at discounted fares during weekdays (with regular fares charged from 7 to 8 AM and 4:30 to 5:30 PM) and all day on weekends and holidays.

In Allegheny County, Pennsylvania the Free Transit Program for Senior Citizens (age $65+$ ) is paid for by proceeds from the Pennsylvania lottery and reimburses the Port Authority for all senior rides. Moreover, in Florida, senior citizens 65 years and older or Social Security beneficiaries who are permanent Miami-Dade County residents are eligible to ride transit free with a Golden Passport.

Other medium-size and smaller agencies with senior free-ride programs include Island Transit in Island County, Washington; the Tri-County Metropolitan Transportation District of Portland, Oregon; the King County Metro in Washington; and the CityLink in Coeur d'Alene, Idaho. The most recent list of such programs can be found elsewhere (Volinski 2012). 


\section{Elasticity Studies}

There have been free-fare demonstrations of fixed-route services, where fares were reduced 100 percent and made free to the general public (not exclusively to seniors, as in this paper), which have resulted in measurable increases in ridership. Denver made off-peak fares free and experienced an increase in total ridership of 36 percent (Doxsey and Spear 1981), and Mercer County, New Jersey, instituted a similar demonstration program and experienced an increase in total ridership of 16 percent (Studenmund and Connor 1982). Austin, Texas, experienced a total ridership increase of 75 percent but adjusted the result attributable to free fares to 10 percent due to the existence of other factors, including increases in service (Perone and Volinski 2003). Perone and Volinski (2003) also reported anticipated increases in total ridership resulting from free fares of approximately 50 percent. A recent survey found ridership increases from 20 to 60 percent "in a matter of just a few months" (Volinski 2012).

Traditional fixed-route transit demand elasticity relies on the "Simpson \& Curtin" demand elasticity-shrinkage ratio, to be more accurate-of -0.33 , meaning for every 1 percent increase in fare, there will be a corresponding $1 / 3$ percent loss of ridership (McCollom and Pratt 2004). An informative discussion about various elasticity measures for transportation demand is provided elsewhere (Pratt 2000).

The American Public Transportation Association (APTA) has done further analysis of fixed bus demand and developed a range of elasticity from -0.18 to -0.43 , depending on peak or off-peak service and size of metropolitan area. This demand elasticity has also been used to predict ridership when fares are reduced. There is no agreement in the industry that the elasticity for fare increases is also valid for fare reductions. However, using this method to predict free fares, a 100 percent decrease in fares would result in an increase in fixed-route ridership between 18 and 43 percent, depending on size of metro area and whether it is peak or off-peak service (APTA 1991).

A later study (Hodge et al. 1994) noted that the reason fare-free programs often result in ridership increases is that there is a substantial psychological impact, at least among riders in smaller communities, when no fare is required. This is because all financial barriers are negated, and the embarrassment of not knowing what the fare is can be avoided, making a fare-free policy much more effective than a simple reduction in fares. The study concluded that smaller communities, especially, are better served by a fare-free policy. In addition, Metaxatos and Dirks (2012) examined the ridership impact of a free-fare policy for ADA complementary paratransit 
service in Illinois and found an estimated average increase in annual ADA trips between 121 and 171 percent in the Chicago area.

\section{Registration Trends}

The Regional Transportation Authority (RTA) in Chicago is responsible for funding, regional planning, and fiscal oversight of all public transportation in the six-county Northeastern Illinois region as provided by three transit operating agencies: the Chicago Transit Authority (CTA), Metra commuter rail (Metra), and Pace suburban bus and paratransit (Pace). When the RTA implemented the Seniors Ride Free (SRF) program starting in October 2008, it created the SRF fare card. Seniors could use existing reduced fare (RF) cards for free rides until April 2009.

Before the April 2009 deadline, eligible riders were counted as registrants in both programs, minus those who had transitioned but whose RF cards had not yet expired. After April 1, 2009, eligible riders were only those registered for the SRF program. The large increases in the numbers of SRF registrants just before the April 2009 deadline when a senior RF card could no longer be used for free rides can be seen in Figure 1. Reduced fare registrations decreased during the SRF program from 252,260 in March 2008 to 175,632 in December 2009. At the same time, SRF registrations increased from under 2,000 in March 2008 to more than 396,000 in December 2009.

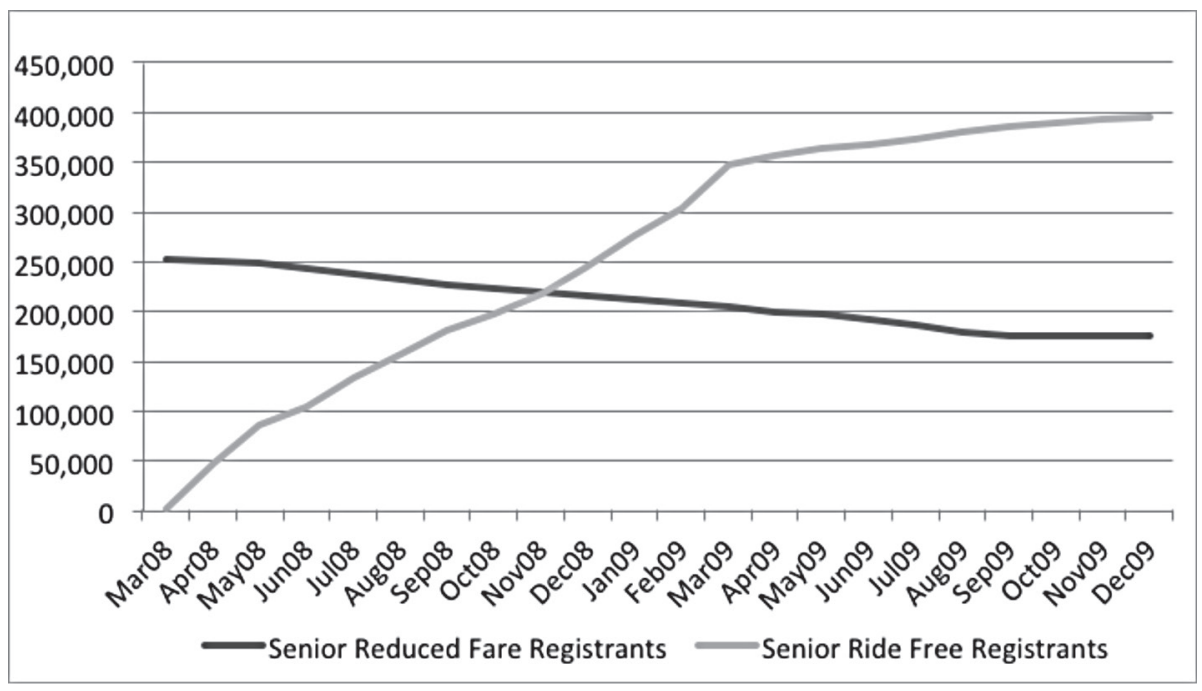

Figure 1. Senior Reduced Fare and Ride Free registrations 


\section{Service Boards Ridership Trends}

On average, the CTA, Metra, and Pace service boards provide more than 52.5 million monthly trips and total ridership experienced an upward trend between January 2007 and December 2009. At the same time, the estimated reduced-fare ridership decreased from 5.5 million to 3.0 million trips (medium-gray color trendline in Figure 2). Moreover, SRF ridership increased sharply during the first few months of the program to 3 million trips by October 2008. Seniors seemed to take fewer free trips during the winter of 2008, but ridership picked up again and peaked at 3.2 million trips in July 2009. By December 2009, SRF ridership had decreased to 2.6 million trips (Figure 2). The implicit assumption in Figure 2 is that the senior reduced-fare ridership prior to March 2008 (light gray trendline) transitioned into senior fare-free ridership after March 2008 (dark gray trendline).

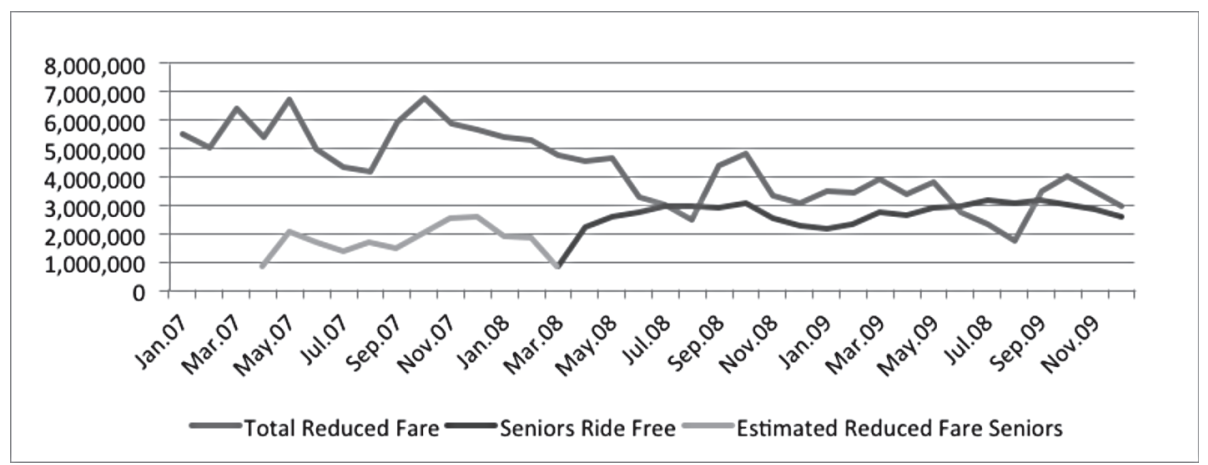

Figure 2. Service board ridership by month

Between March 2008 and December 2009, seniors took a total of 58.4 million free rides on the RTA system. This represents five percent of total ridership. In the same period, Metra estimated about 3.7 percent of total ridership was free trips for seniors. In addition, free rides for seniors provided during the same period represented 5.1 percent of CTA's ridership and 6.3 percent of Pace's total ridership.

\section{Short-Term Ridership Impacts of the SRF Program}

The short-term ridership impact of the SRF program is the sum of two trends: (a) diversion of senior rides, previously on reduced fare, to free rides, and (b) attraction of new free rides to the SRF program. Prior to March 2008 when the SRF program was enacted, CTA, Metra, and Pace did not register senior riders separately from other reduced fare riders, which included persons with disabilities, military personnel, students, and children. Therefore, to estimate diversion of rides from the 
reduced fare program to the SRF program, the differences in reduced fare rides were computed for each month from before and after the SRF program went into effect, starting from April 2007 and ending in March 2008-the assumption being that seniors who had being paying a reduced fare were no longer doing so and were riding free. These differences provide an estimate of the senior reduced-fare ridership prior to the start of the SRF program in March 2008 (Figure 2). The average of these monthly differences is an estimate of the diverted rides (call this Estimate A).

To estimate the total number of new free rides attracted to the SRF program for the same period, the total monthly SRF ridership was averaged (call this Estimate $B)$. The estimated number of new rides was then computed to be the difference between Estimates $\mathrm{A}$ and $\mathrm{B}$.

The following examples illustrate the method above. Consider the reduced-fare senior ridership change for April 2007 and April 2008 (the first full month of the SRF program). The estimated April 2008 ridership (as a percentage of total ridership) was 2.5 percent lower than that in April 2007 (Table 1). In addition, in April 2008, all Service Boards reported 2,200,905 SRF rides representing 4.0 percent of the total ridership (Table 1). As a result, the short-term impact of the SRF program for April 2008 is the $4.0 \%-2.5 \%=$ $1.5 \%$ gain in new free rides (Table 1). The impact for other months is calculated similarly.

\section{Table 1. Service Board Free Rides and Reduced-Fare Rides Diversion}

\begin{tabular}{|l|c|c|c|c|c|}
\hline $\begin{array}{l}\text { Monthly } \\
\text { Difference }\end{array}$ & $\begin{array}{c}\text { RF* Rides, } \\
\text { Difference from } \\
\text { 1 Year Ago }\end{array}$ & $\begin{array}{c}\text { RF Rides, } \\
\text { Difference from } \\
\text { 1 Year Ago (\%) }\end{array}$ & $\begin{array}{c}\text { Free } \\
\text { Rides }\end{array}$ & $\begin{array}{c}\text { Free } \\
\text { Rides } \\
\text { (\%) }\end{array}$ & $\begin{array}{c}\text { Difference between } \\
\text { Free Rides and RF } \\
\text { Rides (\%) }\end{array}$ \\
\hline Apr-07-08 & $-814,138$ & $-2.5 \%$ & $2,200,905$ & $4.0 \%$ & $1.5 \%$ \\
\hline May-07-08 & $-2,033,146$ & $-4.0 \%$ & $2,589,894$ & $4.6 \%$ & $0.6 \%$ \\
\hline Jun-07-08 & $-1,705,309$ & $-3.6 \%$ & $2,713,811$ & $4.9 \%$ & $1.3 \%$ \\
\hline Jul-07-08 & $-1,355,133$ & $-3.1 \%$ & $2,925,219$ & $5.1 \%$ & $2.0 \%$ \\
\hline Aug-07-08 & $-1,681,666$ & $-3.4 \%$ & $2,963,729$ & $5.3 \%$ & $1.8 \%$ \\
\hline Sep-07-08 & $-1,484,020$ & $-3.5 \%$ & $2,868,513$ & $5.0 \%$ & $1.5 \%$ \\
\hline Oct-07-08 & $-1,980,104$ & $-3.9 \%$ & $3,131,494$ & $5.1 \%$ & $1.3 \%$ \\
\hline Nov-07-08 & $-2,526,688$ & $-5.0 \%$ & $3,124,623$ & $6.1 \%$ & $1.1 \%$ \\
\hline Dec-07-08 & $-2,584,132$ & $-5.8 \%$ & $3,117,332$ & $6.5 \%$ & $0.7 \%$ \\
\hline Jan-08-09 & $-1,920,024$ & $-3.8 \%$ & $3,192,162$ & $6.5 \%$ & $2.7 \%$ \\
\hline Feb-08-09 & $-1,831,578$ & $-3.9 \%$ & $3,386,573$ & $6.9 \%$ & $3.0 \%$ \\
\hline Mar-08-09 & $-860,257$ & $-2.1 \%$ & $4,033,241$ & $7.5 \%$ & $5.5 \%$ \\
\hline Average & $-1,731,350$ & $-3.7 \%$ & $3,020,625$ & $5.6 \%$ & $1.9 \%$ \\
\hline
\end{tabular}

* Reduced Fare 
The average percentage decrease in reduced-fare senior riders between April 2008 and March 2009 from a year earlier was 3.7 percent, or 1,731,350 rides (Table 1). This is the estimated average diversion of senior rides previously on RF to SRF rides (Estimate $A$ effect). During the same period the average percentage increase in free SRF rides was 5.6 percent, or an estimated 3,020,625 rides (Estimate B effect). Therefore, the average percentage gain in new rides was $5.6 \%-3.7 \%=1.9 \%$ (Table 1), or an estimated 1,289,275 rides.

Figure 3 shows the respective ridership results. The ridership impact of the first effect (Estimate $A$ ) is shown as bars going downwards (in darker gray), whereas the ridership impact of the second effect (Estimate B) is shown as bars going upwards (in light gray).

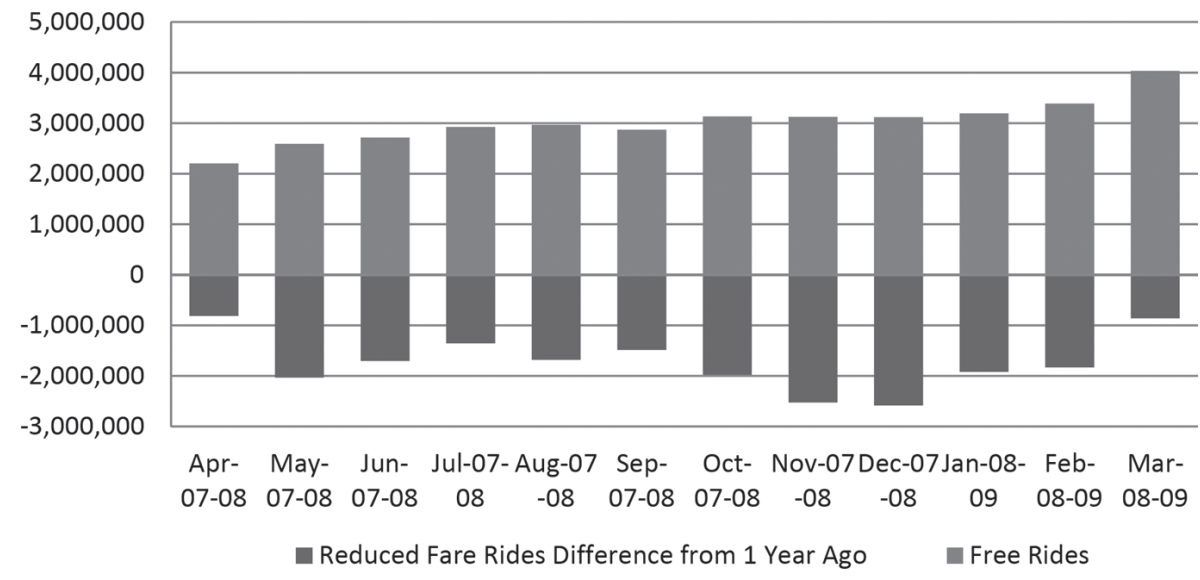

Figure 3. Service boards reduced fare rides diversion and free rides

It should be noted that ridership is impacted by other factors as well. During the study period, gasoline prices fluctuated significantly and unemployment in the Chicago region increased. These and other factors influence both general ridership and usage by seniors.

Since the inception of the SRF program, many seniors who previously were eligible for a reduced fare but were not registered had signed up for the additional benefit resulting in a rapid increase in ridership compared to the previous reduced fare program. Through March 2009, according to the estimates above, the program had attracted, on average, 1.3 million new free rides per month compared to an average 1.7 million seniors rides per month with previously reduced fares. This represents a 
75 percent increase in ridership, which is not to be confused with a potential overall ridership increase, which is more difficult to calculate since people not registered for the RF program's travel habits were not analyzed.

\section{Short-Term Revenue Impact of the SRF Program}

Ideally, one would like to measure the financial implications of the SRF program by comparing two identical systems, one with and one without such a program. Unfortunately, this was not practical to do. This paper also does not discuss the impacts following the program modification in 2011. However, we can assess the revenue loss to the RTA by estimating the revenue that could have been collected if everyone riding free at the time were to pay a fare. This is done in the section below entitled "A Survey Free Approach."

There are several difficulties with such an approach. One is that it does not take into account additional rides seniors take because rides had become free. One way to incorporate this into our analysis was to compare the present with the situation before the program went into effect. This is not entirely fair since the impact of decreasing fares might not be negative (or the reciprocal of increasing fares). Still, that analysis is possible and is presented below for the SRF program. An advantage of using information from the survey is that it enables incorporation of holders of SRF cards or RF cards who actually use them. A disadvantage of any survey-based approach is just that-it is based on a survey, with all attendant biases, such as nonresponse bias and recall bias.

The survey-free approach is discussed first because it is probably simpler to implement and demonstrates the feasibility of the evaluation method if survey data are not available. Later, two survey-based approaches are discussed using slightly different assumptions and provide flexibility for the analyst in the presence of available survey data.

\section{A Survey-Free Approach}

If everyone riding free at the time were to pay a fare, a question arises as to what fare-full fare or a reduced fare? Using two different fares-the average reducedfare revenue on the low end and the full base fare on the high end-we can compute a range of revenue losses. Since seniors typically pay a reduced fare, one might conjecture that the actual revenue loss would be closer to the lower end of the range. 
Average full cash (reduced-fare) fares were computed by dividing the total number of rides paying full cash fare (reduced fare) into the total revenue collected. The weighted average reduced-fare revenue per ride is based on actual usage as computed by each service board. Fare and ridership information was obtained from each service board.

The 2009 annual revenue loss for the SRF program is estimated to be between $\$ 26.1$ million (based on average reduced-fare revenue loss) and $\$ 76.8$ million (based on full-cash-fare revenue loss) with a median value (based on the weighted average reduced-fare revenue per ride above) of $\$ 38.5$ million (Table 2).

Table 2. Estimated Range of Revenue Loss of SRF Program, 2009

\begin{tabular}{|l|c|c|c|}
\hline $\begin{array}{c}\text { Service } \\
\text { Board }\end{array}$ & $\begin{array}{c}\text { Average Reduced Fare } \\
\text { Revenue Loss }\end{array}$ & $\begin{array}{c}\text { Estimated Weighted Average Fare } \\
\text { Revenue Loss }\end{array}$ & $\begin{array}{c}\text { Full Cash Fare } \\
\text { Revenue Loss }\end{array}$ \\
\hline CTA & $\$ 18,084,520$ & $\$ 26,817,744$ & $\$ 63,479,205$ \\
\hline Metra & $\$ 6,738,920$ & $\$ 9,939,907$ & $\$ 10,007,296$ \\
\hline Pace & $\$ 1,269,840$ & $\$ 1,725,566$ & $\$ 3,316,745$ \\
\hline Total & $\$ 26,093,280$ & $\$ 38,483,217$ & $\$ 76,803,246$ \\
\hline
\end{tabular}

\section{A Survey-Based Approach}

A survey of registered seniors was undertaken to identify the habits of free ride users and determine whether they had changed their public transit usage because they were paying no fare. It is generally understood that shorter time frames for recalling events and experiences produces more valid information (Stone et al. 2000). Our experience with the survey of seniors seems to corroborate this observation. As a result, survey-based analysis was as reliable as the recall ability of the seniors responded.

In this light, we discuss two methods for estimating the revenue loss of the SRF program based on a survey of SRF cardholders. Both methods provide a means to estimate the revenue loss one week before and one week after the SRF Program started. This estimate, when considered on an annual basis, can then be compared to the figures estimated by the previous "survey-free" approach.

\section{Sampling Issues}

The population of registered SRF cardholders was sampled by area of residence: City of Chicago, the rest of Cook County, and collar counties (DuPage, Kane, Lake, McHenry, and Will). Initially, two options were available: (a) sample in proportion 
to the number of seniors in each area or (b) sample in proportion to the number of seniors with senior free cards in each area. The second way seemed to be preferable because the target population was the seniors with SRF cards. Indeed, seniors with an RTA Senior Ride Free card are, in general, proportionally fewer in the collar counties (Table 3). This is not surprising, given the lower availability of transit in the collar counties. Had we ignored this fact and sampled in proportion to the number of all seniors in each area, we would have obtained a very different sample. The mail-out-mail-back survey was to a random sample of 5,000 seniors in July 2009 and achieved an overall return rate of 39.3 percent.

Table 3. Senior Population in RTA Region

\begin{tabular}{|l|c|c|c|c|c|}
\hline \multirow{2}{*}{ County } & \multicolumn{2}{|c|}{ Population Age 65+* } & \multicolumn{2}{c|}{ Seniors with SRF Card** } & $\begin{array}{c}\text { Total } \\
\text { Population }\end{array}$ \\
\cline { 2 - 5 } & Number & Percent & Number & Percent & $5,294,664$ \\
\hline Cook & 624,187 & $11.79 \%$ & 213,808 & $4.04 \%$ & 930,528 \\
\hline DuPage & 100,835 & $10.84 \%$ & 61,737 & $6.63 \%$ & 507,579 \\
\hline Kane & 43,543 & $8.58 \%$ & 18,596 & $3.66 \%$ & 712,453 \\
\hline Lake & 68,863 & $9.67 \%$ & 46,953 & $6.59 \%$ & 318,641 \\
\hline McHenry & 32,125 & $10.08 \%$ & 19,644 & $6.16 \%$ & 681,097 \\
\hline Will & 57,505 & $8.44 \%$ & 19,993 & $2.94 \%$ & $8,444,962$ \\
\hline Total & 927,058 & $10.98 \%$ & 380,731 & $4.51 \%$ & \\
\hline
\end{tabular}

*Table 1: Annual Estimates of the Resident Population for Counties of Illinois, April 1, 2000, to July 1, 2008 (CO-EST2008-01-17). Source: Population Division, U.S. Census Bureau, release date March 19, 2009.

**Data from RTA.

\section{Highlights of Survey Results}

The following results pertain to transit use: (a) 44 percent of the respondents did not have a reduced fare card prior to the SRF program; (b) 34 percent of the respondents at the time of the survey used transit one or more times per week; (c) 28 percent responded that they ride transit more frequently as a result of the program; (d) an approximately equal percentage (31\%) reported they use cars and taxis less.

In regard to why and how they ride: (a) 13 percent reported taking rides that are work related while 16 percent were employed; (b) 47 percent reported having ridden CTA bus in the week prior to the survey, 25 percent CTA rail, 31 percent Metra, and 17 percent Pace; (c) 50 percent of respondents reported taking more transit trips during rush hour, and 52 percent rode more during weekends since the SRF 
program started. These findings are in general agreement with two recent surveys of seniors in the Chicago area (Mohammadian et al. 2009; Mueller and Jane 2007).

The socioeconomic profile of the respondents included the following: (a) more than 90 percent were living in households of 1 or 2 people; (b) 79 percent had a driver's license, and 81 percent had an auto available; (c) 16 percent were employed at the time of the survey, 5 percent less than at the start of the SRF program; (d) 33 percent had incomes less than $\$ 22,000$ annually; (e) 28 percent had income more than $\$ 55,000$ annually; (f) 44 percent of the respondents (taking 59 percent of the rides) would qualify for free rides based only on income eligibility (vis-à-vis seniority).

Finally, 71 percent of respondents thought the SRF program should be continued, whereas 24 percent thought it should be limited to low-income seniors; the remaining 4 percent thought the SRF program should be discontinued. However, seniors living in less affluent households in the city, who are frequent riders and live alone or with somebody else, have a markedly more positive attitude toward the SRF program compared to those living in more affluent households in the suburbs, who are infrequent riders and live in larger families.

\section{Estimating Revenue Loss Using the Deflation Difference Method}

The Deflation Difference method computes the difference in revenue generated by riders between a typical week before March 17, 2008, the starting date of the SRF program (the "before" period) and a week in the first half of June 2009 (the "after" period). The number of rides in the "before" period was estimated as the difference between the number of rides in the "after" period and the additional number of rides seniors reported taking since the SRF program started.

In addition, in the absence of actual usage by seniors of RF and SRF cards, qualitative information from survey responses regarding frequency of card use was quantified as follows:

- Seniors using an RF or SRF card "None of the time" would pay the full fare all the time.

- Seniors using an SRF card "About a quarter of the time" would pay the full fare about $75 \%$ of the time and ride free about $25 \%$ of the time.

- Seniors using an RF card "About a quarter of the time" would pay the full fare about $75 \%$ of the time and half fare about $25 \%$ of the time; this is equivalent to paying the full fare about $87.5 \%$ of the time. 
- Seniors using an SRF card "About half the time" would pay the full fare about $50 \%$ of the time and ride free about $50 \%$ of the time.

- Seniors using an RF card "About half the time" would pay the full fare about $50 \%$ of the time and half fare about $50 \%$ of the time; this is equivalent to paying the full fare about $75 \%$ of the time.

- Seniors using an SRF card "More than half the time" would pay the full fare about $25 \%$ of the time and ride free about $75 \%$ of the time.

- Seniors using an RF card "More than half the time" would pay the full fare about $25 \%$ of the time and half fare about $75 \%$ of the time; this is equivalent to paying the full fare about $62.5 \%$ of the time.

- Seniors using an SRF card "All the time" would pay the full fare none of the time (ride free all the time).

- Seniors using an RF card "All the time" would pay the half fare all the time; this is equivalent to paying the full fare $50 \%$ none of the time.

It should be noted that without knowing the exact riding behavior of seniors (for example, by comparing the RF and SRF card use of the same riders before and after the SRF program started), we could not assign more specific values to qualitative responses such as "about a quarter of the time," "about half the time," or "more than half the time."

All but the fare information was obtained from the survey of SRF cardholders. The fare information was made available by each service board and is the same information used in other survey-free approaches discussed earlier in this paper. The discussion below provides the mathematical definitions and expressions for the necessary computations.

Let $i$ and $j$ index, respectively, the frequency of use of RF cards (in the "before" period) and SRF cards (in the "after" period). Let $x_{i j}$ be the number of rides in each of the $(i, j)$ categories taken by SRF cardholders in the "after" period who also had an RF card in the "before" period. The total number of rides, $x_{+j}$, for this group, at each level $j$ of SRF card use, is $x_{+j}=\sum_{i} x_{i j}$. Similarly, the total number of rides, $x_{i+}$, at each level of SRF card use $j$ for RF cardholders who now use a SRF card is. $x_{i+}=\sum_{j} x_{i j}$. In the "after" period, there were also a number of rides taken by SRF cardholders who did not have an RF card in the "before" period. Let's call the number of rides at 
each level $j$ of SRF card use for this group $x_{+j}{ }^{\text {(no RF) }}$. Clearly, the total number of rides taken by SRF cardholders in the "after" period is $X_{++}=\sum_{j} X_{+i}+X_{+j}{ }^{(\text {no RF) }}$.

Let $z_{i j}$ be the number of additional rides in each of the $(i, j)$ categories taken by SRF cardholders in the "after" period who also had an RF card in the "before" period. The total number of rides for this group at each level $j$ of SRF card use is $z_{+j}=\sum_{i} z_{i j}$. Similarly, the total number of additional rides at each level $j$ of SRF card use for RF cardholders who now use a SRF card is $z_{i+}=\sum_{j} z_{i j}$.

In the "after" period, there were also a number of additional rides taken by SRF cardholders who did not have an RF card in the "before" period. Let's call the number of rides at each level $j$ of SRF card use for this group $z_{+j}{ }^{(n o R F)}$. Clearly, the total number of additional rides taken by SRF cardholders in the "after" period is $z_{++}=$ $\sum_{j} z_{+j}+z_{+j}{ }^{(n o R F)}$.

An estimate of the number of rides in the "before" period can be obtained by taking the difference of $x_{i j}$ 's and $z_{i j}$ 's. More specifically, the total number of rides taken by RF cardholders at each level $j$ of RF card use in the "before" period is $y_{i+}=x_{i+}-z_{i+}$.

In the "before" period, there were also a number of rides taken by seniors who did not have an RF card. Note that these rides would not appear separately in the service boards ridership (reduced-fare or SRF) counts. An estimate of the total number of rides taken by seniors who did not have an RF card in the "before" period is $y_{++}{ }^{\left({ }^{\circ} \mathrm{RF}\right)}=\sum_{j} X_{+j}{ }^{(n o R F)}-z_{+j}{ }^{(n o R F)}$.

Let $u_{i}$ and $v_{j}$ be the portion of full fare for a particular level $i$ of RF card use, and level $j$ of SRF card use, respectively. Let $u_{i}^{*}=u_{i} \times\left(2008\right.$ fare) and $v_{j}^{*}=v_{j} \times(2009$ fare $)$ be, respectively, the quantities $u_{i}$ and $v_{j}$ after absorbing fare information in the "before" and "after" periods.

The computation of the above quantities is done for each service board with specific ridership and fare profiles. Let's now discuss the revenue generated in the "before" and "after" periods.

Following the discussion above, the total revenue per week generated by SRF riders in the "after" period is $R^{(a f t e r)}=\Sigma_{j}\left[\left(x_{+j}+x_{+j}{ }^{(n o R F)}\right) \times V_{j}^{*}\right]$. Similarly, the total revenue per week generated by RF riders in the "before" period is $R^{(\text {before })}=\Sigma_{i}\left(y_{i_{+}} \times u_{i}^{*}\right)+y_{++}{ }^{(\text {no RF) }} \times(2008$ fare). This is because seniors in the "before" period without an RF card would be paying the full 2008 fare.

The total revenue loss per week for each service board is then simply $R=R^{(\text {before })}$ $R^{(a f t e r)}$. Using this method, the total revenue loss estimate of the SRF program was 
estimated to be $\$ 34.4$ million per year, $\$ 4.1$ million less than the median estimated loss of the survey free approach discussed earlier (Table 4).

Table 4. Deflation Difference Method vs. Survey-Free Approaches

\begin{tabular}{|l|c|c|c|c|}
\hline \multirow{2}{*}{$\begin{array}{c}\text { Service } \\
\text { Board }\end{array}$} & \multicolumn{4}{|c|}{ Revenue Loss Using } \\
\cline { 2 - 5 } & $\begin{array}{c}\text { Deflation Difference } \\
\text { Method }\end{array}$ & $\begin{array}{c}\text { Average } \\
\text { Reduced Fare }\end{array}$ & $\begin{array}{c}\text { Average Full } \\
\text { Cash Fare }\end{array}$ & $\begin{array}{c}\text { Estimated Weighted } \\
\text { Average Fare }\end{array}$ \\
\hline CTA & $\$ 30,794,970$ & $\$ 18,084,520$ & $\$ 63,479,205$ & $\$ 26,817,744$ \\
\hline Metra & $\$ 1,612,289$ & $\$ 6,738,920$ & $\$ 10,007,296$ & $\$ 9,939,907$ \\
\hline Pace & $\$ 1,944,686$ & $\$ 1,269,840$ & $\$ 3,316,745$ & $\$ 1,725,566$ \\
\hline Total & $\$ 34,351,945$ & $\$ 26,093,280$ & $\$ 76,803,246$ & $\$ 38,483,217$ \\
\hline
\end{tabular}

\section{Estimating Revenue Loss Using the Deflation Ratio Method}

The Deflation Ratio method operates on the entire table of SRF rides taken by seniors with and without a prior RF card, not just at the margins. If this were the only difference, the two methods would give identical results. A second difference between the two methods is that the "before" period ridership (obtained by taking the difference between SRF rides and additional SRF rides as discussed in the Deflation Difference method) is not used directly into the revenue loss calculation; it is rather used to compute "deflation factors" of the SRF ridership, as explained below. Let $d_{i j}=\frac{y_{i j}}{x_{i j}}$, the ratio of SRF ridership $\left(x_{i j}\right)$ and RF ridership $\left(y_{i j}\right)$ be the deflation factor of SRF ridership for a particular $(i, j)$ category of RF and SRF card use. Recall that the weekly RF ridership can only be indirectly estimated as the difference between the weekly SRF ridership and the additional number of SRF rides in that same week. As a result, whenever the number of additional rides reported is greater than SRF ridership because of recall issues, the deflation factor is set equal to 1the SRF ridership in each category of card use would logically be larger than the RF ridership given that the SRF Program has attracted additional rides. The deflation factor is also set equal to 1 in cases where particular $(i, j)$ categories are absent. A missing value analysis could have rendered less arbitrary values for those few cases. Available methods for this problem are discussed elsewhere (Brownstone 1998; Wang and Shao 2003; Cox 2002; Metaxatos 2009).

Let also $p_{i j}=\frac{x_{i j}}{x_{++}}$be the percentage of all SRF rides, $x_{++}=\Sigma_{i} \Sigma_{j} x_{i j}$, in each $(i, j)$ category. Following the notation in the previous section, the total revenue loss per week (for each service board) is: 


$$
\begin{gathered}
R=R^{(\text {before })}-R^{(\text {after })}= \\
\sum_{i} \sum_{j} y_{i j} u_{i}^{*}-x_{i j} v_{j}^{*}=\sum_{i} \sum_{j} d_{i j} x_{i j} u_{i}^{*}-x_{i j} v_{j}^{*}=\sum_{i} \sum_{j} d_{i j} p_{i j} x_{++} u_{i}^{*}-x_{i j} v_{j}^{*} \\
=\sum_{i} \sum_{j} d_{i j} p_{i j} x_{++} u_{i}^{*}-p_{i j} x_{++} v_{j}^{*}=\sum_{i} \sum_{j} p_{i j}\left(d_{i j} u_{i}^{*}-v_{j}^{*}\right) x_{++}
\end{gathered}
$$

where,

$$
\left\{\begin{array}{c}
d_{i j}=1 \text { if }\left(x_{i j}=0 \text { or } x_{i j}<y_{i j}\right) \\
\text { and } \\
0 \leq d_{i j}<1, \text { otherwise }
\end{array}\right.
$$

$$
\forall i \in\left\{\begin{array}{c}
i_{1}=\text { None of the time } \\
i_{2}=\text { About a quarter of the time } \\
i_{3}=\text { About half the time } \\
i_{4}=\text { More than half the time } \\
i_{5}=\text { All the time } \\
i_{6}=\text { No RF card before SRF program }
\end{array}\right\}, \forall j \in\left\{\begin{array}{c}
j_{1}=\text { None of the time } \\
j_{2}=\text { About a quarter of the time } \\
j_{3}=\text { About half the time } \\
j_{4}=\text { More than half the time } \\
j_{5}=\text { All the time }
\end{array}\right\}
$$

The following three examples will illustrate the method. In the first example, let's assume that $0.2 \%$ of the rides were taken by seniors who had but did not use a reduced fare card or a SRF card. Therefore, the weekly revenue loss for this category would be:

$$
\begin{gathered}
0.2 \% \times[100 \% \times(\text { full fare }) \times(\text { weekly RF ridership })- \\
100 \% \times(\text { full fare }) \times(\text { weekly SRF ridership })]= \\
{[0.2 \% \times(\text { full fare }) \times(100 \% \times(\text { weekly RF ridership })]-} \\
{[100 \% \times(\text { weekly SRF ridership })]=} \\
0.2 \% \times[(\text { deflation factor }) \times 100 \%-100 \%] \times \\
(\text { weekly SRF ridership }) \times(\text { full fare })
\end{gathered}
$$

In a second example, let's assume that $0.02 \%$ of the rides were taken by seniors who had but did not use an RF card, and use a SRF card (approximately) 25\% of the time. Therefore, the weekly revenue loss for this category would be:

$$
\begin{gathered}
0.02 \% \times[100 \% \times(\text { full fare }) \times(\text { weekly RF ridership })- \\
75 \% \times(\text { full fare }) \times(\text { weekly SRF ridership })]= \\
0.02 \% \times(\text { full fare }) \times[(100 \% \times(\text { weekly RF ridership })- \\
75 \% \times(\text { weekly SRF ridership })]= \\
0.02 \% \times[(\text { deflation factor }) \times 100 \%-75 \%] \times \\
(\text { weekly SRF ridership }) \times(\text { full fare })
\end{gathered}
$$


In the third example, let's assume that $0.24 \%$ of the rides were taken by seniors who used an RF card (approximately) 25\% of the time and never use a SRF card. Therefore, the weekly revenue loss for this category would be:

$0.24 \% \times\{[(25 \% \times($ half fare $)+(75 \% \times($ full fare $)] \times($ weekly RF ridership $)-$

$[100 \% \times($ full fare $) \times($ weekly SRF ridership $)]\}=$

$0.24 \% \times($ full fare $) \times[(87.5 \% \times($ weekly RF ridership $)-(100 \% \times 2009$ SRF ridership $)]=$ $0.02 \% \times[$ (deflation factor $) \times 87.5 \%-100 \%] \times($ weekly SRF ridership $) \times($ full fare $)$

Using the same ridership and fare information for each service board as above, the Deflation Ratio method estimates the total annual revenue loss of the SRF program to be $\$ 34.9$ million, about $\$ 0.5$ million more than the deflation difference method and about $\$ 4.6$ million less than the previous survey free approach (Table 5).

Table 5. Deflation Ratio Method vs. Survey-Free Approaches

\begin{tabular}{|l|c|c|c|c|}
\hline \multirow{2}{*}{$\begin{array}{c}\text { Service } \\
\text { Board }\end{array}$} & \multicolumn{4}{|c|}{ Revenue Loss Using } \\
\cline { 2 - 5 } & $\begin{array}{c}\text { Deflation Ratio } \\
\text { Method }\end{array}$ & $\begin{array}{c}\text { Average Reduced } \\
\text { Fare }\end{array}$ & $\begin{array}{c}\text { Average Full Cash } \\
\text { Fare }\end{array}$ & $\begin{array}{c}\text { Estimated Weighted } \\
\text { Average Fare }\end{array}$ \\
\hline CTA & $\$ 26,880,499$ & $\$ 18,084,520$ & $\$ 63,479,205$ & $\$ 26,817,744$ \\
\hline Metra & $\$ 6,589,925$ & $\$ 6,738,920$ & $\$ 10,007,296$ & $\$ 9,939,907$ \\
\hline Pace & $\$ 1,466,571$ & $\$ 1,269,840$ & $\$ 3,316,745$ & $\$ 1,725,566$ \\
\hline Total & $\$ 34,936,995$ & $\$ 26,093,280$ & $\$ 76,803,246$ & $\$ 38,483,217$ \\
\hline
\end{tabular}

\section{Discussion of the Results from the Survey-Free and Survey-Based Methods}

The results obtained using the deflation difference and the deflation ratio methods should not be too far apart. The former method operates on the margins of the table of SRF rides taken by seniors with and without a prior RF card, while the latter operates on the entire table. Overall, recall issues with survey respondents affect the deflation factor method more than the deflation difference method (generally speaking, ratios magnify between-periods fluctuations more than differences).

In the particular application discussed in this paper, seniors in 7 out of 25 categories of frequency of SRF and RF card use for Metra reported having made more RF rides than SRF rides. Note that only one such category for Pace and none for CTA exhibit the same phenomenon. An additional issue with the deflation ratio method is that a few of the categories above are absent: three for CTA, four for Metra, and seven for Pace. 
An advantage of using the deflation ratio method vis-à-vis the deflation difference method is that it allows using SRF ridership from different sources. For example, we could have used the actual SRF ridership (obtained from the service boards) increased by a survey-based estimate of rides taken by seniors without their SRF card (these rides would not have been recorded separately as senior rides). In any case, both survey-based methods estimate a total revenue loss closer to the one estimated by a survey-free method based on a weighted average fare. Therefore, the total revenue loss can be reasonably estimated to range between $\$ 34.3$ and \$38.4 million.

\section{Conclusions}

The magnitude of the short-term financial loss for the SRF program raises questions about the financially sustainability of the program, especially considering the demographic projections of the regional senior population. In fact, under conservative scenarios, the SRF program would have doubled its revenue losses by 2030 (Dijohn et al. 2010). Indeed, Illinois legislators may have been thinking along these lines when they decided to roll back the SRF program and make it available only as a means-tested program starting in September 2011. The methods discussed, however, provide the tools for relevant ridership and revenue impact evaluations of existing and future free-fare transit programs.

It should be noted, however, that the estimated revenue loss reported in this paper will not directly translate into revenue gains. This is because it is reasonable to assume (based on the survey information) that after the revision of the SRF program about 60 percent of the senior rides would be free based on income eligibility. The potential "gain" would be further deflated under the assumption that some seniors would simply stop riding because it would no longer be free.

Nevertheless, this paper discussed several approaches to evaluate the ridership and revenue impact of a policy decision such as the one that, at least temporarily, allowed seniors to ride public transportation for free in Illinois. In an era of very tight budgets among transit operators, it has become more critical than ever to assess the implications of such policies, preferably before implementation. However, when there is a need to conduct such an assessment during a fare-free program implementation, the methods proposed in this paper would add to the toolbox that transit planners use and eventually contribute to improving the understanding of similar policy decisions. 


\section{Acknowledgments}

This paper was made possible by the support of the Metropolitan Transportation Support Initiative in the Urban Transportation Center of the University of Illinois at Chicago. We would also like to acknowledge the assistance from RTA, CTA, Metra, and Pace in providing all data necessary to complete the analysis.

\section{References}

American Public Transportation Association. 2005. Most seniors worry about being stranded without transportation. Transit News, December.

American Public Transportation Association. Effects of fare changes on bus ridership. http://www.apta.com/research/info/online/elastic.cfm. Accessed July 2011.

Ammon, G. 2008. Driving retirement planning: A good investment. National Center on Senior Transportation 1(5): 2.

Brownstone, D. 1998. Multiple imputation methodology for missing data, nonrandom response and panel attrition. Theoretical Foundations of Travel Choice Modeling: 421-449.

Cox, L. H. 2002. Imputing missing values in two-way contingency tables using linear programming and Markov Chain Monte Carlo. UNECE Work Session on Statistical Data Editing, Working Paper 39.

Dijohn, J. et al. 2010. Analysis of the RTA seniors and people with disabilities ride free programs. Final Report. Regional Transportation Authority, Chicago, Illinois, November.

Doxsey, L. B., and B. D. Spear. 1981, Free-fare transit: Some empirical findings. Transportation Research Record 799: 47-49.

Hodge, D. C., et al. 1994. Fare-free policy: Costs, impacts on transit service, and attainment of transit system goals. Report No. WA-RD 277.1. Washington State Department of Transportation, March.

McCollom, B. E., and R. H. Pratt. 2004. Traveler response to transportation system changes: Chapter 12-Transit pricing and fares. TCRP Report 95. onlinepubs. trb.org/onlinepubs/tcrp/tcrp_webdoc_12.pdf. Accessed 7/17/12. 
Metaxatos, P. and L. Dirks. 2012. Cost estimation of fare-free ADA complementary paratransit service in Illinois. Journal of Public Transportation 15(4): 67-85.

Metaxatos, P. 2009. Issues with small samples in trip generation estimation. In Transportation Statistics, Brian W. Sloboda. Ed. Ft. Lauderdale: J. Ross Publishing: 123-149.

Mohammadian, K., et al. 2009. Effectiveness of transit strategies targeting elderly people: Survey results and preliminary data analysis. Research Report ICT-09033. Illinois Center for Transportation, February.

Mueller, M., and T. Jane. 2007. Understanding senior's unmet transportation needs. Leo J. Shapiro \& Associates. August 1.

Perone, J. S., and J. M. Volinski. 2003. Fare, free or something in between? Center for Urban Transportation Research, University of South Florida.

Stone, A. A., et al. 2000. The Science of Self-Report: Implications for Research and Practice. Mahwah, NJ: Lawrence Erlbaum.

Studenmund A. H., and D. Connor, 1982. The free-fare transit experiment. Transportation Research 15(4): 261-270.

U.S. Bureau of the Census. 2008. Projections of the total resident population by 5-year age groups and sex, with special age categories, middle series 1999-2100 (NP-T3).

Volinski, J. M. 2012. Implementation and outcomes of fare-free transit systems: A synthesis of transit practice. TCRP Synthesis 101. (onlinepubs.trb.org/onlinepubs/tcrp/tcrp_syn_101.pdf, accessed 7/17/12).

Wang, H., and J. Shao. 2003. Two-way contingency tables under conditional hot deck imputation. Statistica Sinica 13: 613-623.

\section{About the Author}

Paul Metaxatos (pavlos@uic.edu) is Associate Director for Research Programs and Research Assistant Professor in the Urban Transportation Center, University of Illinois at Chicago. He has conducted numerous transit planning studies in Illinois. He recently advised the Regional Transportation Authority in Chicago about the ridership and cost implications of a free-fare ride program for seniors and people with disabilities. 